\title{
The Linearity of Verb Copying Cleft Construction in Chinese: Semantic Underspecification and Pragmatic Enrichment
}

\author{
Moying Li \\ Dongfang College, Zhejiang University of Finance and Economics, China \\ Lian Zhang \\ Zhejiang University of Finance and Economics, China
}

\begin{abstract}
In Standard Chinese, verb doubling cleft construction (henceforth VDCC) has received little attention in the linguistic literature. Recently, Cheng and Vicente (2013) claim that VDCC has the same internal syntax as regular clefts, and two verbs stand in A-bar movement relation based on the lexical identity effect. In this paper, we argue that (1) VDCC is derived in line with the principle of linearity; (2) the first verb is a reduced minimal form acting as a topic which is pragmatically enriched via contextual information; (3) the second verb is interpretively dependent on the first verb.
\end{abstract}

Index Terms - verb copying cleft construction, lexical identity effect, linearity, minimal form, frame setting

\section{INTRODUCTION}

In Standard Chinese, verb doubling cleft construction (henceforth VDCC), as illustrated by example (1) below, has received little attention in the linguistic literature:

(1) 吃, 我是吃过了, 不过...

Chi, wo shi chi guo le, buguo...

eat I COP eat EXP LE but

'As for eating, I have (indeed) eaten, but...'

Recently, having treated the two verbs in VDCC as standing in an A-bar movement relation, Cheng and Vicente (2013) claim that VDCC in Chinese has the same internal syntax as regular clefts, rather than being an independent construction. In this paper we argue that VDCC in Chinese is not derived via movement. It is generated in line with the principle of linearity or relative to context. The first verb is a reduced minimal form acting as a topic, whose interpretation would be pragmatically enriched via context; the second verb is interpretively dependent on the first verb.

This paper is structured as follows. In section 2, we mainly present a critical review of the analysis proposed by Cheng and Vicente (2013). Section 3 proposes an account of the first verb in VDCC in terms of semantic underspecification and pragmatic enrichment. Section 4 discusses the relationship between the first verb and the second verb. A conclusion is made in section 5 .

\section{EXISTING ANALYSIS}

In this section, we will critically review Cheng and Vicente (2013)'s analysis on VDCC, which adopts the hypothesis laid out in Cheng (2008). Cheng (2008) claims that the morpheme shi in Chinese is a copular verb taking a small clause with pro predicate, as (2) shows:

(2) $s h i$ [sc[subJeCTXP][PREDpro]]

The pro predicate then raises to the left of shi and forms inverse predication structure, which is structurally equivalent to the English cleft counterpart "it is x":

(3) $[p r o]_{i} s h i\left[{ }_{\text {sc }}\left[\right.\right.$ suBjeCT $_{\text {XP }}\left[t_{\mathrm{i}}\right]$

The constituent immediately following shi is the focus of the cleft. And other constituents of the SC subject may appear to the left of $s h i$, which is taken as the topic via movement, as listed in (4):

(4) 王五是昨天看见了李四。

[TWangwu] shi [Fzuotian] kanjian le Lisi.

Wangwu COP yesterday see LE Lisi

'It is yesterday that Wangwu saw Lisi.'

According to Cheng and Vicente (2013), verb doubling clefts in Standard Chinese also display the same distribution of topic and focus like (3). "The first instance of the verb, being to the left of shi, is interpreted as a topic. Similarly, the second instance of the verb following shi, is interpreted as a (part of the) focus" (Cheng and Vincente, 2013, p.5), as can 
been seen in (5):

(5) Q: 你吃过饭没有?

$\mathrm{Ni}$ chi-guo fan meiyou?

you eat-EXP rice not.have

'Have you eaten already?'

$\mathrm{A}$ : 吃, 我是吃过, 不过...

[т Chi], [т wo ] shi [Fchi-guo], buguo...

Eat I COP eat-EXP but

'As for eating, I have indeed eaten, but...' (Cheng and Vicente, 2013, p. 5)

Note that the focus in (5) is a verum focus rather than a contrastive one, which affirms the truth of the proposition (see also Krifka, 2007). This requires that focalized element is not the lexical verb itself but the event. VDCC in Chinese also triggers an adversative implicature: The meaning of the cleft is true, some additional contextual factors need to be taken into account, as indicated by buguo 'but'.

The two verbs are in A-bar movement chain on the basis of lexical identity effects, and they need to be lexically identical. "It is not possible for one of them to further specify the other" (Cheng and Vicente, 2013, p. 9):

(6) a. 旅行, 我是坐过飞机。

$*$ Lüxing, wo shi zuo-guo feiji.
travel I COP sit-EXP airplan

'As for travelling, I have taken a plane.'

b. 者菜, 我是烤过鸡。

*Zhucai, wo shi kao-guo ji.

Coo-meal, I COP roast-EXP chicken

'As for cooking a meal, I have indeed roasted chicken.'

Based on the lexical identity effect, Cheng and Vicente (2013) state that "a verbal constituent undergoes A-bar movement out of the focus position and into a topic position"(p.9). They then conclude that verb doubling clefts and regular clefts are derived from the same syntactic frame. The verum reading (as opposed to the contrastive focus reading of regular clefts) arises as a consequence of the fact that the upper copy of verb is interpreted as a topic (see also Bastos, 2001).

However, Cheng and Vicente's claim should be untenable, since we can use another verb to specify the first verb:

(7) 旅行, 我是乘火车去的, 不过很难受。

Lüxing, wo shi cheng huochequ de, buguo hen nanshou.

travel I COP take train go DE but very uncomfortable

'As for travelling, I have indeed taken a train, but it is very uncomfortable.'

In (7), the second verb phrase is also a verum focus to affirm the truth of the topic expressed by the first verb. And an additional meaning buguo hen nanshou 'it is very uncomfortable' can also be taken into account. (6b) is unacceptable because topic and comment are not in an aboutness relation. ${ }^{1}$ The aboutness relation constrains the comment in the sense that it should be expressed with respect to topic. According to the $6^{\text {th }}$ edition of the contemporary Chinese dictionary, $z h u$ 'boil' is defined as "put foods or other things into pot with water to burn". In Standard Chinese, zhucai should not be translated as 'cook meal'. Actually, it is a common expression in Cantonese not in Standard Chinese. As a result, zhucai 'boil meal' and kaoji 'roast chicken' are not in an aboutness relation, since they are two different processes of cooking (for detailed discussion, see section 4). Normally, we can see the following expression zuofan, wo shi chaoguo xihongshi, buguo bu haochi 'As for cooking a meal, I have indeed stir-fried tomato. But it is not delicious '. The verb chao 'stir-fry' is a subcategory of the verb zuofan 'cook a meal', which can be used to specify zuofan 'cook a meal'.

There is another hypothesis adopted in Cheng and Vicente (2013)'s analysis, that is, topic is derived from movement. In the next section, we will demonstrate that topic is generated via linearity. The first verb is an actual anaphora structure based on the context.

\section{TOPIC AND THE FIRST VERB IN VDCC}

In this section, we will argue in the first place that topic is derived in line with the principle of linearity rather than movement based on the hierarchy structure. Second, we will propose that the first verb appearing in the initial position is actually semantically underspecified topic which needs to be enriched pragmatically.

\section{A. The Linearity of Topic}

Chao (1968) declares that "the grammatical meaning of subject and predicate in a Chinese sentence is topic and comment, rather than actor and action. Actor and action can apply as a particular case of topic and comment, as in Goou

\footnotetext{
1 Aboutness relation means that the comment clause is always about topic. That is to say, topic expression has a semantic or pragmatic relation with comment. Portner and Yabushita (1998) provide a semantic account of aboutness, claiming that "the semantic representation of the topic phrase must be part of the sentence's background" (Portner and Yabushita 1998, p.149).
} 
yeau ren "Dog bites man" (p.19).Chinese has generally been considered a topic-prominent language, whereas English is regarded as a subject-prominent language (Li and Thompson, 1976, 1981).

Huang, et al. (2009) claim that "a topic structure refers to a sentence that has a phrase 'preposed' to the position before the subject. The use of the term 'preposed' is suggestive of movement"(p.202). Movement means that topic is derived by movement and related to a gap in the comment (cf. Huang, 1982, 1984; Shi, 1992, 2000). According to Huang (1982), Chinese topic structure is akin to English wh-questions in that they are both generated via movement. Under the movement analysis, both structures must obey a constraint, namely, island condition. Extraction is impossible from within certain domains, such as NP island and wh-island, as shown in (8) below:

(8) *小明, 我认识[很多 $\left[\mathrm{e}_{\mathrm{i}}\right.$ 讨厌]的]人]。

*Xiaoming, wo renshi [henduo [ $\mathrm{e}_{\mathrm{i}}$ taoyan] de] ren].

Xiaoming 1SG know many hate DE people

*As for xiaoming $\mathrm{i}_{\mathrm{i}}$, I know many people who $\mathrm{e}_{\mathrm{i}}$ hates.

$\mathrm{Xu}$ and Langendoen (1985) argue that topic structures are not derived from movement:

(9) 这本书 ${ }_{\mathrm{i}}$, 买过 $\mathrm{e}_{\mathrm{i}}$ 的人不多

Zhe ben $s h u_{\mathrm{i}}$, mai guo $\mathrm{e}_{\mathrm{i}}$ de ren buduo.

This-CL book buy PRT DE people not many

As for this book, there aren't many people who have bought.

Maiguo zhebenshu de ren 'many people who have bought this book' forms a NP island, which means that no element can be moved out. The acceptability of (9) demonstrates that Chinese topic structures are not subject to the island constraint.

In Standard Chinese, topic and its comment may have a syntactic relation as well. According to Chafe (1976), this type of topic can be classified as "English-style". In Chinese, the topic that does not have any syntactic relation with its comment is called "Chinese-style" (see Chafe, 1976), or "dangling" or "hanging" topic (cf. Shi 2000; Pan and Hu 2008):

(10) 语言学, 张三偏爱语义学。

yuyanxue, Zhangsan pianai yuyixue.

linguistics Zhangsan prefer semantics

'As for linguistics, Zhangsan prefers semantics.

First, we need to emphasize that topic expression is essentially a discourse concept, as exemplified below:

(11) Speaker A: 您还甭说, 这最近河南留住一个人才, 这个人才当了郑州市规划局的什么副局长。

ninhaibengshuo, zhe zuijin Henan liuzhu yi ge

you know that this recently Henan province keep one CL

rencai, zhege rencai dang le zhengzhoushi

qualified-person this-CL qualified-person become EXP Zhengzhou city

guihuajü de shenme fujüzhang.

planning bureau DE what deputy director general

'You know that, Henan province recently keeps a qualified person, who becomes the deputy director general of Planning Bureau in Zhengzhou city.'

Speaker B: 逯军。

Lu Jun.

'Lu Jun is his name.'

Speaker A:已经被网友们封为历史上最“牛”副局长。

Yijing bei wangyou men feng wei lishishang

already Passive netizen Plural grant as in history

zui 'niu' fujüzhang.

most arrogant deputy director general

'He has been granted as the most arrogant deputy director general in history by netizens.'

Speaker B: 最“牛”副局长。

zui 'niu' fujüzhang.

most arrogant deputy director general

'the most arrogant deputy director general.'

Speaker A: ......这位副局长, 怎么说呢? ......也倒霉。

......zhe wei fujüzhang, [zenmeshuone]?

this CL deputy director general what to say

.....ye daomei.

also bad luck

'...... This deputy director general, what to say? ...... is in bad luck.' (Phoenix TV/Behind the healines with Wen Tao/2009-06-25) 
(12)他的居室......怎么说呢? 做饭炉子, 空酒瓶子, 锅碗墂盆, 垃圾煤堆, 报刊杂志, 床铺像个货摊。 ta de jushi..... [zenmeshuone]? zuofan luzi, kong jiu pingzi,

he DE living room what to say? cook oven empty wine bottle

guo wan piao pen, laji meidui,

pot bowl wooden dipper basin rubbish coalpile

baokan zazhi, chuangpu xiang ge huotan.

newspaper magazine bed like CL booth

'As for his living room....... what to say? cooking oven, empty winebottles, pot, bowl, Wooden dipper, basin, rubbish, coalpile, newspaper and magazine are on the bed, which is like a booth.' (Yan Gang/Think of GuoXiaochuan)

Zhewei fujüzhang 'this deputy director general' in the last utterance of (11) is a topic expression, which is elicited at the discoursal level. That is to say, the topic expression zhewei fujüzhang 'this deputy director general' is constructed as the conversation develops. Interlocutors are familiar with it. Zhewei fujüzhang 'this deputy director general' refers to and coindexes with guihuajü fujüzhang 'the deputy director general of Planning Bureau and zuiniu fujüzhang 'the most arrogant deputy director general', which have already occurred in the previous utterance. After the topic has been produced, zenmeshuone 'what to say' appears right behind it. zenmeshuone 'what to say' is a parenthetical construction, being self-sufficient and gapless in structure. No syntactic relation exists in the linguistic units appearing before and behind it. In (11) and (12), zenmeshuone 'what to say' is used to show speakers' uncertainty towards the topic expressions. (12) is a typical Chinese-style or dangling topic construction. Tadejushi 'his living room' is a noun phrase topic expression. The parenthetical construction zenmeshuone 'what to say' acts as a topic orientation marker to show the hesitation attitude towards the topic expression tadejushi 'his living room'. It is usually used in cases where, speaker shoots out a topic, and then gets stuck just like a recorder, that is, s/he has no idea how to find words to comment the topic. Technically speaking, when the topic expression first appears and holds the initial position of a sentence, the comment has not been formed. That is, the syntactic representation of comment actually does not exist. As a result, we cannot move any linguistic unit out of the comment.

As has been illustrated above, linearity is the fundamental basis on which topic structure in Chinese is generated. Frank et al. (2012) point out if language use is best explained by sequential structure, then linguistic phenomena that have previously been explained in terms of hierarchical syntactic relationships may be captured by factors relating to sequential constrains, semantic considerations or pragmatic context "(p. 4526).Thus, we can conclude that the linear order "Topic [Subject+VP]" is the basic syntactic representation of topic construction in Standard Chinese (for detailed discussion, see Yang and $\mathrm{Wu}, 2015)$.

\section{B. The First Verb in VDCC}

In section 3.1.1, we claim that topic is essentially a discoursal concept (see also C. Huang, 1992), which is naturally elicited during the course of communicative interaction in line with the principle of linearity. Cheng and Vicente (2013) point out that the first verb in VDCC is a copied verb moved to the left periphery of the $v \mathrm{P}$. In this section, we will argue that the first verb, as a VP anaphor, is also a topic, which will first occupy the initial position of a clause, following the principle of linearity.

During the course of communicative interaction, we can employ VP anaphor (henceforth VPA) to refer to the previous event. VPA is a cross-linguistic phenomenon existing in English, Hebrew, Chinese, Korean and Japanese (see de Boer, 1992). Hankamer and Sag (1976) make a distinction between surface anaphora and deep anaphora. Surface anaphors are syntactically controlled, in that they need a linguistic antecedent of a particular syntactic form. Deep anaphors are pragmatically controlled referents requiring the appropriate semantic type in context, as can be illustrated in below:

(13) A peace agreement in the Middle East needs to be negotiated.

a. An agreement between India and Pakistan does too. (verb phrase ellipsis-surface anaphora)

b. Hilary Clinton volunteered to do it. (event anaphora- deep anaphora)

In (13b), deep anaphora is interpreted with respect to a discourse model, that is, the semantic representation of the event "negotiate a peace agreement".

In VDCC, the first verb is an event anaphora elicited from the context, as can be seen in (5), repeated as (14):

(14) Q: 你吃过饭没有?

$\mathrm{Ni}$ chi-guo fan meiyou?

you eat-EXP rice not.have

'Have you eaten already?'

A: 吃, 我是吃过, 不过...

[T Chi], [т wo ] shi [F chi-guo], buguo...

Eat I COP eat-EXP but

'As for eating, I have indeed eaten, but...'

In (14), the first verb chi 'eat' is semantically somewhat underspecified in the sense that some information seems missing and consequently the utterance seems incomplete. In this situation, the first verb must be enriched 
pragmatically with reference to the linguistic context. Under this context, it is actually the representation of the event chifan 'eating', which has been expressed in the interrogative utterance above. Thus, we can say that the first verb in VDCC is a VPA dependent on the context. According to Kehler and Ward (2004), the reference to the antecedent event should account for two aspects of discourse understanding: The process of modeling the sources of information, ${ }^{2}$ and the constraints on the use of referring expressions with respect to these knowledge sources. In VDCC, VPA is employed to refer to the previous event on the basis of the discourse status. ${ }^{3}$ The event chifan 'eating' represented by the first verb in VBCC is discourse-old (see Prince, 1992), since it has previously been introduced, which means that the verb event is familiar to interlocutors in context. Based on source of information and discourse status, a VPA device can be employed to refer to the previous event.

The first verb in VDCC also corresponds to the principle of being efficient in grammar (see Hawkins, 2004). "Crucially, efficiency is an inherently relative notion that compares alternative form-property pairings for expressing the same proposition, and the (most) efficient one that has the lowest overall complexity in on-line processing" (Hawkins, 2004, p. 25). Minimize Forms (MiF) displays the concept of being efficient in grammar with the idea of "expressing the most with the least" (Hawkins, 2004, p. 25). MiF underlies the Economy Principle observed by Zip (1949). Hawkins (2004) also argues that a minimized form is also preferred as long as the intended contextually appropriate meaning can be recovered from reduced linguistic forms with more general meanings. Then the principle of Minimize Forms is defined as follows:

The human processor prefers to minimize the formal complexity of each linguistic form F (is phoneme, morpheme, word, or phrasal units) and the number of forms with unique conventionalized property assignments, thereby assigning more properties to fewer forms. These minimizations apply in proportion to the ease with which a given property $\mathrm{P}$ can be assigned in processing to a given F. (Hawkins, 2004, p.38).

Topic, as a discoursal concept, can be taken as a property given to a form. Linguistic form bears a property on what the sentence is about. When the topic has been mentioned in context, interlocutors intend to use a reduced form in performance, such as pronoun:

(15) A：你看见小明了?

$\begin{array}{llll}\mathrm{Ni} & \text { kanjian } & \text { Xiaoming } & l e ? \\ \text { you } & \text { see } & \text { Xiaoming } & \mathrm{LE}\end{array}$

'Have you seen Xiaoming?'

B: 他呀, 去图书馆了。

Ta ya, qu tushuguan le.

He particle go library LE

'He went to the library.'

$(15 \mathrm{~B})$ is the answer to (15A). The third personal pronoun $t a$ is a reduced form topic to refer to Xiaoming in order to increase the efficiency in communication. Normally, compared with full NPs, pronouns are semantically under-specified in terms of reference resolution. When the discourse context makes an entity highly accessible, people prefer to using the minimal form rather than full NPs. Ariel (1990) and Brizuela (1999) also point out that more accessible entities are referred to by shorter and more reduced forms, e.g. by pronouns rather than full NPs via quantitative studies in English and other languages. (15) clearly shows that when interlocutors can recognize the topic, they often assign this property to a reduced form in performance.

Hankamer and Sag (1976) note that an explicit VP anaphor, as in "it is not clear that you will be able to do it", can have either a textual antecedent (I am going to jump over the wall) or a situational one (in which someone is trying to jump over the wall). This tellingly reveals the fact that a deep anaphor should be pragmatically enriched on the condition that a more accessible entity or event should be mentioned previously or existing in context. Otherwise, a minimal form would cause more processing effort in communication. Human processor prefers to copying syntactic and semantic content from a target onto a minimal form. The minimal form relies on the target for its enrichment. Kempson (1977) discusses the following sentences "one day I will kick the bucket and you will do so" and "one day I will kick the bucket and you will too". She points out that the anaphoric and empty VPs in the second conjunct must be interpreted with reference to the meaning of "kick the bucket" in the first conjunct. Enrichment of the minimal forms is made on the basis of the target. Compared with a full VP, a verb is a minimal form but under-specified in semantic content. Nonetheless, a verb is crucial to describe the meaning of a verbal event and determines the occurrences of other components of the event. When there is a highly accessible verb event mentioned previously, verb is the preferred reduced form to represent the event.

Now let us consider VDCC. In (14), the target is the event chifan 'eating'. Chi 'eat' is the minimal form whose

\footnotetext{
2 Several sources of information constrain the use of referring expressions. First, speaker should have a belief about the know ledge of hearer. Second, speaker should have a belief about hearer's representation of the entities and eventualities in discourse. A third source is the context of discourse consisting of the entities and eventualities currently mentioned. Prince (1992) describes that the discourse-status of an entity or an event depends only on whether the entity or the event has already been introduced into the discourse. For example, the book in the second clause is discourse-old:

(i) I borrowed a book from the library yesterday. The book is very interesting.

${ }^{3}$ Prince (1992) states that the discourse-status of an entity or an event depends only on whether the entity or the event has already been introduced into the discourse. For example, the book in the second clause is discourse-old:

(i) I borrowed a book from the library yesterday. The book is very interesting.
} 
syntactic structure and semantic content can be enriched from the target. It also manifests the concept of being efficient as the topic. In section 3.1.1, we demonstrate that topic structure is constructed in line with the principle of linearity, which means that topic occurs first and occupies the initial position of a sentence/utterance. This captures the "Express it earliest" intuition in performance, which is defined as Maximize On-line Processing (MaOP) (Hawkins, 2004, p.51):

The human processor prefers to maximize the set of properties that are assignable to each item $\mathrm{X}$ as $\mathrm{X}$ is processed, thereby increasing On-line Property to Ultimate Property ratios. The maximization difference between competing orders and structures will be a function of the number of properties that are unassigned or misassigned to $\mathrm{X}$ in a structure/sequence $\mathrm{S}$, compared with the number in an alternative.

The notion of unassignment means that a specific syntactic or semantic property should be assigned earlier in a sequence. "Speech is a linear sequence of forms and properties, each of which contributes to the ultimate syntactic and semantic representation for a sentence" (Hawkins, 2004, p.28). The earlier the property is assigned, the more efficient the communication is. This predicts that distribution should favor earlier rather than later property assignments. Topic is a property assigned to the linguistic form occupying the initial position of a sentence. MaOP then predicts that the linearity of topic structure should be preferred, which would increase the efficiency in grammar and in communication. The linear order "Topic [Subject+VP]" would be associated with significant assignments on-line corresponding to the "Express it earliest" intuition. There could also be significant assignments of prior or highly accessible discourse entity or event to a minimal form as a topic.

To sum up, we can conclude that linearity is the basic principle under which the syntactic representation of topic construction in Standard Chinese is constructed, which corresponds to the principle of MaOP embodying the "Express it earliest" intuition in context. As a topical element, the first verb in VDCC, as a VPA anaphor, is the reduced minimal form used to refer to the previous event and occupies the initial position of a clause in line with the linear order.

\section{THE SECOND VERB IN VDCC}

According to Cheng and Vicente (2013), the second verb in VDCC is the main verb occupying the subject position of a small clause. Then it is copied and then is extracted out of a small clause subject to the left periphery of the $v \mathrm{P}$. In this section we will propose that the second verb is dependent on the frame of the event expressed by the first verb.

Dependency relation between two verbs

Jacobs (2001) lists several dimensions of topic-comment structure (TC). First, topic is informationally separated from the comment, where the topic is introduced and its semantic meaning is processed in a first step, and then, in a second step, the comment is added. Second, topic is the address for comment iff topic marks the point in the speaker-hearer knowledge where the information carried by comment has to be stored at the moment of the utterance that is produced. "Addressation can be viewed as an explication of the intuitive notion of aboutness" (Jacobs, 2001, p.655). Third, topic is the frame for comment in that it specifies a domain to which the proposition expressed by comment is restricted.

The first dimension embodies the linearity of topic construction. The second dimension stresses that topic is a discoursal concept. The third dimension demonstrates that comment is dependent on topic, not vice versa. "Ordering the topic first permits the parser to assign the dependent properties to the predication immediately as it is parsed, whereas ordering the predication first would delay assignment of these properties until the following topic is encountered" (Hawkins, 2004, p. 235). Topic introduces a background, against which an utterance will be interpreted. As pointed out in section 2, Cheng and Vicente (2013)'s proposal starts from the hypothesis of lexical identity effect, which suggests that the two verbs must be lexically identical. And it is impossible for one verb to specify the other (Cheng and Vicente, 2013). The frame-setting dimension can illustrate that lexical identity effect is not the basis for Cheng and Vicente (2013)'s analysis. Topic introduces a background and guides the semantic processing of the comment clause. In VDCC, the second verb alone is also semantically underspecifed. Without any specific context or any reference, we would be unable to comprehend what the second verb chi 'eat' in (14) is intended to mean. Its interpretation relies on the topic meaning represented by the first verb, which is a pragmatic process of enrichment dependent on the topic. Interpretively, the underspecified meaning expressed by the second verb will be substituted by the event conveyed by the first verb. In Standard Chinese, there are also similar examples showing the same dependent relationship between topic and comment:

(16) 这块地呀, 麦子长得好。

Zhe kuai di ya, maize zhang de hao.

this piece land particle wheat grow DE well

'As for this piece of land, wheat grows well.'

In (16), predication is enriched by topic through providing the locative meaning. In VDCC, the second verb alone is also semantically underspecifed. Without any specific context or any reference, we would be unable to comprehend what the second verb chi 'eat' in (14) is intended to mean. Its interpretation relies on the topic meaning represented by the first verb, which is a pragmatic process of enrichment dependent on the topic. In VDCC, the first verb provides the frame or domain relative to which the second verb is interpreted, as in (17):

(17) Q: 你旅行过没有?

$\mathrm{Ni}$ lüxing guo meiyou?

you travel EXP not.have 
'Have you travelled already?'

A: 旅行, 我是乘火车去的, 但是不舒服。

Lüxing, wo shi cheng huoche qu de, travel I COP take train go DE buguo hen nanshou.

but very uncomfortable

'As for travelling, I have indeed taken a train, but it is very uncomfortable.'

Lüxing 'travelling' sets a frame or domain for the second verb. We can then use the specific verb to further illustrate the first verb, such as the manner of traveling. Hence, the two verbs may not be lexical identical. They have to belong to the same domain. Normally, the first verb should be the general one, whereas the second one should be the specific one to further illustrate the event represented by the first verb.

The dependency relation between topic and comment also determines the verum focus of the second verb. Höhle (1992) carries out an in-depth investigation of verum focus in German. Verum focus emphasizes the truth of proposition of a sentence, as opposed to information focus or contrastive focus, as can be seen in below:

(18) A: I wonder whether John has finished his job.

B: John has finished his job.

(18) discusses John's status by A's question. B can use a focal stress on the auxiliary has to emphasize the truth of the proposition that John has finished his job. Verum is a cross-linguistic phenomenon (see Gutzmann and Miró, 2011). Compared with information focus, verum focus has no influence on the truth condition of the proposition. Gutzmann and Miró (2011) claim that verum focus is use-conditional instead of being truth-conditional (see also Romero, 2005). Thus, Romero and Han (2004, p. 627) defines that it is "used not to assert that the speaker is entirely certain about the truth of $p$, but to assert that the speaker is certain that $p$ should be added to the Common Ground (CG)."According to this definition, we can conclude that the verum focus interpretation expressed by the second verb in VDCC must be dependent on the common ground represented by the first verb. This also adequately explains why (6b) listed in Cheng and Vicente (2013) is illicit. As has been pointed out, zhucai 'boil meal' is not a general verb phrase to mean 'cooking meal' in Standard Chinese. It is only a general verb phrase for boiling, which is a subcategory of cooking meal. If zhucai 'boil meal' is the topic, then it will set a frame of boiling for comment or predication. Kaoji 'roast chicken' cannot be used to specify zhucai 'boil meal' since it is not a subcategory of boiling.

\section{CONCLUSION}

In this paper, we have presented an account of Chinese verb doubling cleft construction, with a particular focus on the two verbs' relations and their respective pragmatic functions in context. We have demonstrated with empirical evidence that two verbs in VDCC are not in A-bar movement relation on the basis of lexical identity effect proposed by Cheng and Vicente (2013). Rather, the first verb, as a topical element, is a VPA device used to refer to the previous event in context. The verum focus interpretation of the second verb is dependent on the frame expressed by the first verb. The occurrences of two verbs actually follow the principle of linearity, which is also the fundamental principle under which topic-comment structure in Standard Chinese is constructed.

\section{REFERENCES}

[1] Ariel, Mira. (1990). Accessing Noun-Phrase Antecedents. London: Routledge.

[2] Bastos, Ana. (2001). Fazer, eu faço! Topicalização de constituents verbais em portugues brasileiro [As for doing, I do! Topicalization of verbal constituents in Brazilian Portuguese]. M.A. thesis, Universidad Estadual de Campinas.

[3] Brizuela, Maquela. (1999). Definiteness types in Spanish: A study of natural discourse. Ph.D. dissertation, Los Angeles: University of Southern California.

[4] Chafe, Wallace. (1976). Givenness, contrastiveness, definiteness, subjects, topics and point of view. In Charles N. Li (ed.), Subject and Topic, 25-55. New York: Academic Press.

[5] Chao, Yuen-ren. (1968). A Grammar of Spoken Chinese. Berkley: University of California Press.

[6] Cheng, Lisa, L.-S. (2008). Deconstructing the shi...de construction. The Linguistic Review 25. 235-266.

[7] Cheng, Lisa, L.-S., and Luis, Vicente. (2013). Verb doubling in Mandarin Chinese. Journal of East Asian Linguistics 22. 1-37.

[8] De Boer, Ale. (1992). A cross-linguistic overview of VP-anaphora. In Bok-Bennema, Reineke and Roeland van Hou (eds.), Linguistics in the Netherlands, 49-60. Amsterdam: John Benjamins.

[9] Frank, Stefan L., Rens Bod, and Morten H. Christiansen. (2012). How hierarchical is language use?” Proc. R. Soc. B, 279. 4522-4531.

[10] Gutzmann, Daniel and Elena Castroviejo, Miró. (2011). The dimensions of verum. In Olivier Bonami, and Patricia Cabredo Hofherr (eds.), Empirical Issues in Syntax and semantics 8. CSSP.

[11] Hankamer, Jorge and Ivan Sag. (1976). Deep and surface anaphora. Linguistic Inquiry, 7. 391-428.

[12] Hawkins, John. (2004). Efficiency and Complexity in Grammars. Oxford: Oxford University Press.

[13] Höhle, Tilman N. (1992). Über verum-fokus im Deutschen. In Jacobs, Joachim (ed.), Informationsstruktur und Grammatik, 112-141, Opladen: Westdeutscher Verlag.

[14] Huang, Chu-ren. (1992). Certainty in functional uncertainty. Journal of Chinese Linguistics 20. 247-287.

[15] Huang, C.-T. James.(1982). Logical relations in Chinese and the theory of grammar." Ph.D. dissertation, Mass: MIT. 
[16] Huang, C.-T. James. (1984). A Note on the Binding Theory. Linguistic Inquiry 14. 554-561.

[17] Huang, C.-T. James., Y-H. Audrey. Li and Yafei Li. (2009). The Syntax of Chinese. Cambridge: Cambridge University Press.

[18] Jacobs, Joachim. (2001). The dimensions of topic-comment.” Linguistics 39. 641-681.

[19] Kehler, Andrew and Gretory, Ward. (2004). Constrains on ellipsis and event reference. In Laurence R. Horn, and Gretory Ward (eds.), Handbook of Pragmatics, 383-403, Oxford: Blackwell.

[20] Kempson, Ruth. (1977). Semantic Theory. Cambridge: Cambridge University Press.

[21] Krifka, Manfred. (2007). Basic notions of information structure. In Caroline Fery, and Manfred Krifka (eds.), The Notions of Information Structure, 13-56, Potsdam: Uniersitätsverlag Potsdam.

[22] Li, Charles N and Sandra A. Thompson. (1976). Subject and topic: A new typology of language. In Charles N. Li (ed.), Subject and Topic, 457-489, New York: Academic Press.

[23] Li, Charles N and Sandra A. Thompson. (1981). Mandarin Chinese: A Functional Reference Grammar. Berkley: University of California Press.

[24] Portner, Paul and Katsuhiko Yabushita. (1998). The semantics and pragmatics of topic phrases. Linguistics and Philosophy 21. 117-157.

[25] Prince, Ellen F. (1992). The ZPG letter: Subjects, definiteness and information-status. In Sandra Thompson, and W, Mann (eds.), Discourse Description: Diverse Analyses of a Fundraising Text, Amsterdam: John Benjamins.

[26] Romero, Maribel, (2005). Two approaches to biased yes/no questions. In Alderete, John, Chung-hye Han, and Alexei Kochetov (eds.), Proceedings of the 24thWest Coast Conference on Formal Linguistics (WCCFL), MA: Cascadilla Cascadilla Proceedings Project.

[27] Romero,Maribel and Chung-hye Han. (2004). On negative yes/no questions. Linguistics and Philosophy, 27. 609-658.

[28] Shi, Dingxu. (1992). The Nature of Topic Comment Constructions and Topic Chains. Ph.D. dissertation, Los Angeles: University of Southern California.

[29] Shi, Dingxu. (2000). Topic and topic-comment constructions in Mandarin Chinese. Language, 76. $383-408$.

[30] Xu, Liejiong and Donald T. Langendoen. (1985). Topic structures in Chinese. Language 61. 1-27.

[31] Yang, Xiaolong., and Yicheng, Wu. (2015). The linearity of topic structures in Chinese. Waiguoyu, 38. 55-63.

[32] Zipf, George K. (1949). Human Behavior and the Principle of Least Effort. Cambridge, Mass: Addison-Wesley Press.

Moying Li is currently a teacher in the Dongfang College, Zhejiang University of Finance and Economics. Her research interests include semantics and American literature.

Lian Zhang is currently a teacher in Zhejiang University of Finance and Economics. Her research interests include semantics and American literature. 